\title{
The effect of icepack cooling on skin and muscle tempera- ture at rest and after exercise
}

\author{
Maurice Mars ${ }^{1}$ (MB ChB, MD) \\ Brian Hadebe ${ }^{2}$ (MBChB) \\ Mark Tufts ${ }^{3}$ (MSc) \\ ${ }^{1}$ Department of TeleHealth, Nelson R Mandela School of Medicine, University of KwaZulu-Natal, Durban \\ ${ }^{2}$ Postgraduate student, private practitioner \\ ${ }^{3}$ Department of Physiology, Faculty of Health Science, University of KwaZulu-Natal, Durban
}

\begin{abstract}
Objective. To compare cooling of skin, subcutaneous fat and muscle, produced by an icepack, at rest and after short-duration exhaustive exercise.

Methods. Eight male subjects were studied. With the subject supine, hypodermic needle-tip thermistors were inserted into the subcutaneous fat and the mid-portion of the left rectus femoris, to a depth of $1 \mathrm{~cm}$ plus the adipose thickness at the site, and a temperature probe was placed on the skin overlying the needle tips. A pack of crushed ice was applied for 15 minutes and temperatures were recorded before, during, and for 45 minutes after icepack application. Thereafter, subjects underwent a ramped, treadmill, $\mathrm{VO}_{2 \max }$ test, an icepack was applied after temperature probes were inserted into the right leg and measurements were made as before.
\end{abstract}

Results. After the treadmill run, skin (Sk), subcutaneous (SC) and muscle (Ms) temperatures (mean \pm standard deviation $(S D)$ ) were $0.9 \pm 1.3,1.0 \pm 0.7$ and $1.3 \pm 0.8^{\circ} \mathrm{C}$ higher than at rest. After 15 minutes of icepack cooling, temperatures fell in the exercised limb by $22.7 \pm 1.5^{\circ} \mathrm{C}$ (Sk), $13.5 \pm 4.2^{\circ} \mathrm{C}(\mathrm{SC})$ and $9.3 \pm 5.5^{\circ} \mathrm{C}(\mathrm{Ms})$ and in the control limb by $20.7 \pm 2.9^{\circ} \mathrm{C}(\mathrm{Sk}), 11.4 \pm 2.0^{\circ} \mathrm{C}$ (SC) and $8.7 \pm 2.6^{\circ} \mathrm{C}(\mathrm{Ms})$. The reductions in temperature were significant in both the control and exercised limbs. Forty-five

\section{CORRESPONDENCE:}

Maurice Mars

Dept of Telehealth

Nelson R Mandela School of Medicine

University of KwaZulu-Natal

Pvt Bag 7

Congella

4013

Tel: 031-260-4543

Fax: 031-260-4737

E-mail mars@ukzn.ac.za minutes after icepack cooling, muscle temperature was still approximately $5^{\circ} \mathrm{C}$ lower in both the rested and exercised muscle $(p<0.001)$. Individual variations in response to cooling were noted.

Conclusions. Cooling of superficial muscle occurs after high-intensity exercise. The degree of cooling is not uniform. This may be due to differences in the sympathetic response to cooling, influencing haemodynamic and thermoregulatory changes after exercise. This needs further investigation.

\section{Introduction}

Local cryotherapy is commonly used in the management of acute muscle injuries. ${ }^{14,20,24,25}$ Despite this, the clinical benefits of cryotherapy for acute muscle injuries are still questioned, because of the lack of suitable randomised controlled studies. $^{3,12}$

Cooling can be achieved using different modalities such as wet ice, crushed-ice packs, dry ice, frozen gel packs, endothermic chemical reaction packs, refrigerant cooling devices, coolant sprays, cold water baths, cooling blankets, cold air and electrical cooling devices. ${ }^{2,5,22,24,33}$ Many of the physiological effects of local cooling have been well described. Cooling reduces metabolic rate, ${ }^{10,26,31}$ local adenosine triphosphate utilisation, ${ }^{34}$ bloodflow, ${ }^{4,10,23}$ the inflammatory response ${ }^{23}$ and oedema formation. ${ }^{6,11}$ Cooling also has an analgesic effect, slows nerve conduction velocity, and decreases muscle spasm and spasticity. 1,15,18,19,28

There is still controversy over what constitutes the optimal modality, duration and frequency of cryotherapy for muscle injury. ${ }^{3}$ The temperature of skin, subcutaneous tissue and muscle has been measured at various depths below the skin before and after different forms of cryotherapy, $2,5,7,14$ and adipose tissue has been shown to have an insulating effect, impairing cooling of the underlying muscle. ${ }^{27,29}$ In resting muscle, there is normally a temperature gradient, with temperature increasing with depth. ${ }^{7,16,32}$ This gradient is altered by cryotherapy.

To date, studies on the use of cryotherapy have only 

investigated subjects at rest. In the athletic setting, it is common to apply an icepack to an injury as soon as the athlete stops competing or training. Depending on the intensity and duration of exercise, the athlete's muscle temperature, core temperature and cardiac output, will have increased. ${ }^{8,16}$ These haemodynamic and temperature changes may affect temperature flux under a cooling pack.

The aim of this study was to investigate the effect of an icepack on muscle cooling following acute exercise and compare it with muscle cooling in the rested state.

\section{Methods}

The study was undertaken with the approval of the Biomedical Ethics Committee of the University of KwaZulu-Natal. Eight adult male volunteers who all exercise on a regular basis, participating in at least four soccer practices and/or matches a week, were studied and all signed informed consent. At a preliminary visit they underwent medical screening and were familiarised with the apparatus and the testing procedures.

On the day of testing, subjects lay supine for 15 minutes to acclimatise to the ambient temperature of the laboratory. They were dressed in running shorts and an athletic vest. The site for measurement of temperatures was determined as the point halfway between the anterior superior iliac spine and the superior pole of the patella. The skinfold thickness was measured at this point using skin callipers (John Bull skinfold callipers, British Indicators, England) and the thickness of adipose tissue was taken as half the skinfold thickness.

A cutaneous temperature probe (YSI 4494, Yellow Springs Instrument Co) was attached to the skin over the middle of the left thigh in the anterior midline. After cleaning the skin with alcohol, and using aseptic techniques, appropriately sterilised 22G hypodermic, needle-tip thermistors, (YSI Inc Precision 5510 series) were inserted into the subcutaneous fat and to a depth of adipose thickness plus $1 \mathrm{~cm}$ into the quadriceps muscle, so as to lie beneath the skin temperature probe. The needles were inserted from the lateral aspect of the thigh such that the barrel of the hypodermic needle was not under the icepack and the needles were taped to the skin to prevent movement. A needle guide was used to assist needle placement at the correct depth in the muscle. The temperature probes and hypodermic thermistors were attached to a YSI 4000A thermometer and each channel was calibrated using the unit's selfcalibration. The needles were cleaned and sterilised according to the manufacturer's instruction after each use.

A $20 \mathrm{~cm} \times 10 \mathrm{~cm} \times 5 \mathrm{~cm}$ pack of crushed ice in a wet towel was then placed longitudinally over the temperature probe and left in situ for 15 minutes. The icepack was not strapped to the subject and no compression other than the weight of the icepack was applied. Temperature measurements were recorded every minute, for 5 minutes before application of the icepack, during the ice application and for 45 minutes after removal of the icepack. Thereafter the hypodermic needle probes and skin temperature probe were removed.

An hour later subjects underwent a ramped $\mathrm{VO}_{2 \max }$ test on a treadmill using a previously described method. ${ }^{21}$ Oxygen consumption and carbon dioxide production was measured using open circuit spirometry (Oxycon Champion, version 4.3 - CE 0434, Jaeger). The spirometer was calibrated daily. On completion of the treadmill run, subjects immediately lay supine on a plinth and the temperature probes were attached and inserted into the right leg as previously described. After 5 minutes, an icepack was applied for 15 minutes and recordings were made as before.

Data are expressed as the mean and one standard deviation and the $95 \%$ confidence interval is given where appropriate. The rate of change of temperature per minute was determined by calculating the difference between successive measurements, at 5 minute intervals ( $\delta \mathrm{y})$, and dividing this by $5(\delta x)$.

Statistical analysis of the differences of means was by paired $t$-test and the differences of means within and between groups by two-way repeated-measures ANOVA with post hoc testing using the Bonferroni test. Alpha was set at $5 \%$.

\section{Results}

The subjects' mean ages, heights and weights were $21.3 \pm$ 3.0 years, $172.5 \pm 6.6 \mathrm{~cm}$ and $61.8 \pm 10.2 \mathrm{~kg}$. The adipose thickness of the right thigh was $0.43 \pm 0.15 \mathrm{~cm}$ and the left $0.43 \pm 0.17 \mathrm{~cm}$. The ambient temperature during the study was $21.3 \pm 1.7^{\circ} \mathrm{C}$. Maximum oxygen consumption was 49.1 $\pm 4.2 \mathrm{ml} \cdot \mathrm{kg}^{-1} \cdot \mathrm{min}^{-1}$ and this was achieved at a respiratory exchange ratio of $1.15 \pm 0.1$. Treadmill running time was 12.2 $\pm 1.1 \mathrm{~min}$.

The changes in skin, subcutaneous tissue and muscle temperatures are shown in Table I and Fig. 1. Exercise elevated skin and subcutaneous muscle temperatures. The

\begin{tabular}{|c|c|c|c|c|}
\hline Time & Control ${ }^{\circ} \mathrm{C}$ & $95 \% \mathrm{Cl}$ & Exercise ${ }^{\circ} \mathrm{C}$ & $95 \% \mathrm{Cl}$ \\
\hline Skin 5 min & $28.8 \pm 1.4$ & $27.6-30.0$ & $29.7 \pm 1.3$ & $28.6-30.8$ \\
\hline Skin 20 min & $8.1 \pm 2.7$ & $5.8-10.4$ & $7.0 \pm 1.2$ & $6.0-8.0$ \\
\hline Skin 65 min & $25.6 \pm 1.3$ & $24.5-26.6$ & $26.4 \pm 1.5$ & $25.1-27.6$ \\
\hline SC $5 \mathrm{~min}$ & $33.1 \pm 1.1$ & $32.2-34.0$ & $34.2 \pm 1.1$ & $33.3-35.0$ \\
\hline $\mathrm{SC} 20 \mathrm{~min}$ & $21.7 \pm 2.2$ & $19.9-23.5$ & $20.7 \pm 5.0$ & $16.5-24.9$ \\
\hline $\mathrm{SC} 65 \mathrm{~min}$ & $28.1 \pm 1.0$ & $27.3-29.0$ & $29.5 \pm 2.2$ & $27.7-31.4$ \\
\hline Ms 5 min & $34.9 \pm 1.2$ & $33.9-35.9$ & $36.3 \pm 1.1$ & $35.3-37.2$ \\
\hline Ms $20 \mathrm{~min}$ & $26.2 \pm 3.5$ & $23.3-29.1$ & $27.0 \pm 7.4$ & $21.6-32.3$ \\
\hline Ms $65 \mathrm{~min}$ & $29.4 \pm 1.1$ & $28.4-31.4$ & $31.0 \pm 3.6$ & $28.8-33.1$ \\
\hline
\end{tabular}





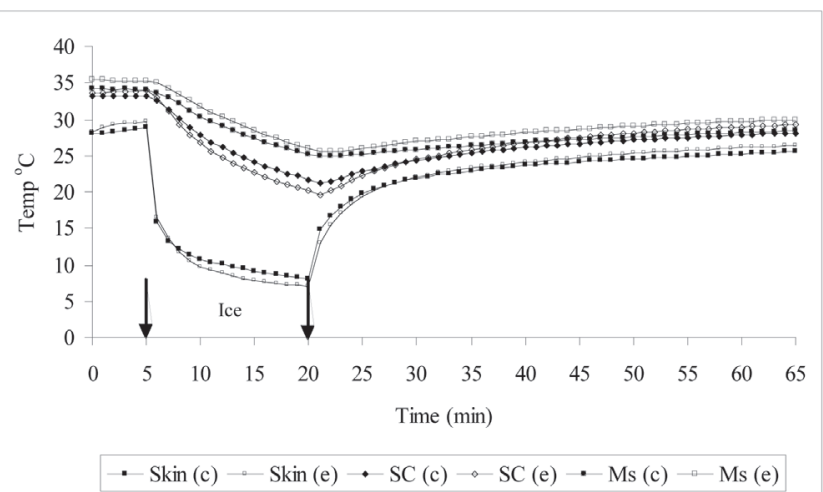

Fig. 1. Mean skin, subcutaneous (SC) and muscle (Ms) temperatures $\left({ }^{\circ} \mathrm{C}\right)$ measured every minute, before, during and after application of an icepack in the rested (c) and exercised (e) limb. The arrows represent the period that the icepack was applied.

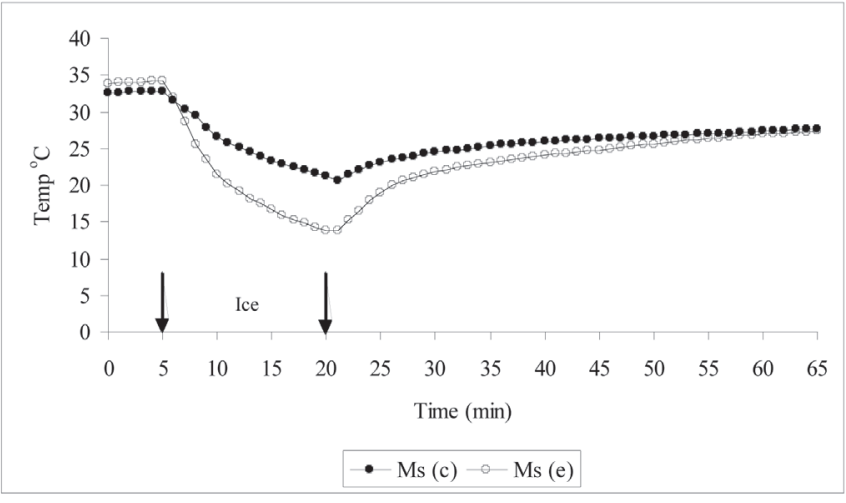

Fig. 2. Muscle temperature recorded every minute, before, during and after application of an icepack in rested (Ms(c)) and exercised muscle (Ms(e)) in subject 1. The arrows represent the period that the icepack was applied.

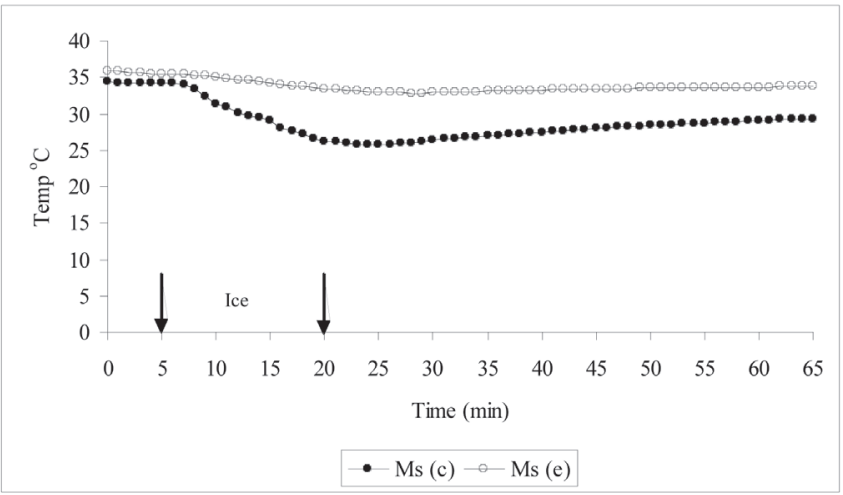

Fig. 3. Muscle temperature recorded every minute before, during and after application of an icepack in rested (Ms(c)) and exercised muscle (Ms(e)) in subject 4. The arrows represent the period that the icepack was applied.

application of the icepack after exercise resulted, on average, in greater cooling of skin, subcutaneous tissue and muscle, with the skin and subcutaneous tissue temperatures falling

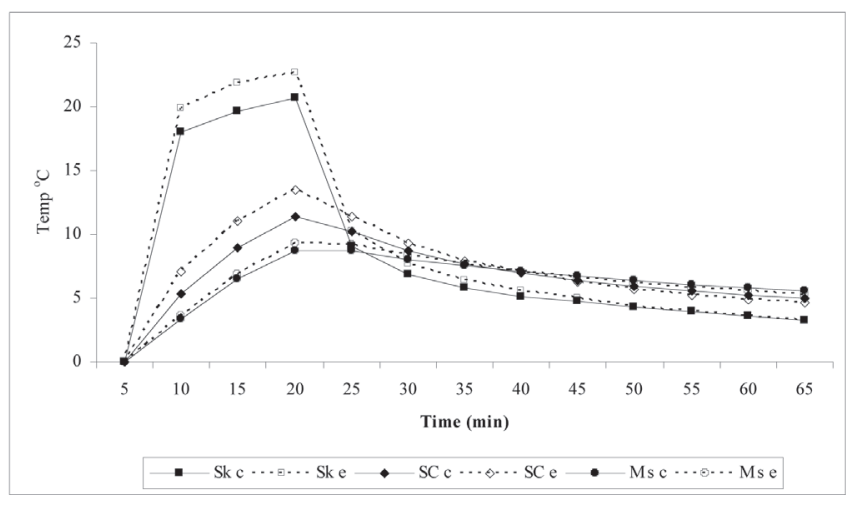

Fig. 4. The absolute change in temperature $\left({ }^{\circ} \mathrm{C}\right)$ from the start of cooling at 5 min and subsequent measurements, of skin (Sk) subcutaneous fat (SC) and muscle (Ms) at rest (c) and after exercise (e). Cooling occurred between $5 \mathrm{~min}$ and $20 \mathrm{~min}$.

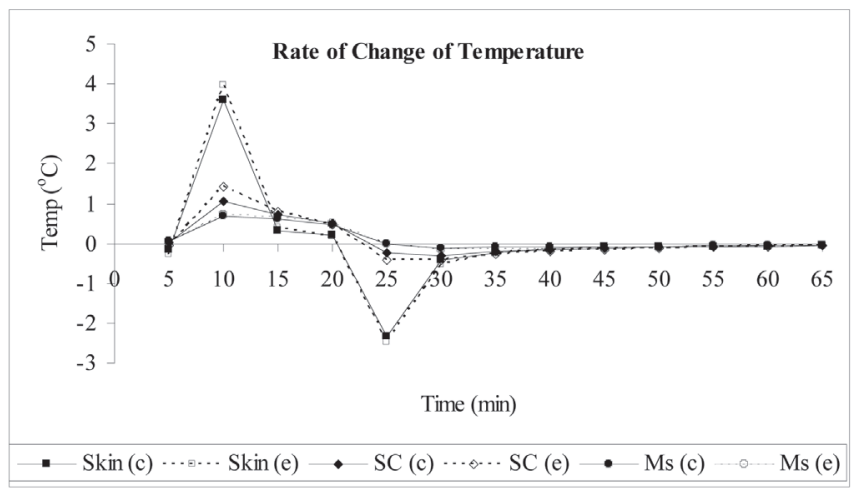

Fig. 5. The average rate of change of temperature per minute of skin, subcutaneous tissue (SC) and muscle (Ms) at rest (c) and after exercise (e).

to below that of the rested limb and then rewarming slightly faster, so as to be higher than the temperatures of the rested limb 45 minutes after removal of the icepack. The average temperature of muscle after exercise did not fall below that achieved in the rested limb during cooling.

This response was not constant and there were individual variations, with some subjects showing a marked reduction in muscle temperature after cooling (Fig. 2) and others showing only minimal cooling of muscle after exercise (Fig. 3).

The time to maximum cooling varied between subjects but was similar for each subject. The average time to maximum cooling of subcutaneous tissue after application of the icepack was $15.1 \pm 0.8 \mathrm{~min},(95 \% \mathrm{Cl}: 15.5-16.7)$ at rest and $16.6 \pm 0.7 \min (95 \% \mathrm{Cl}: 16.1-17.1)$ after exercise and in muscle $20.1 \pm 4.5 \mathrm{~min}(95 \% \mathrm{Cl}: 17.0-23.2)$, range $15-29$ min at rest and $20.4 \pm 3.8 \mathrm{~min}(95 \% \mathrm{Cl}: 17.7-23.0)$, range 16 - $28 \mathrm{~min}$, after exercise (Fig. 1). The differences were not statistically significant.

Skin, subcutaneous and muscle temperatures were compared at three fixed time points, 5 minutes after 
commencing measurement (that is, just prior to the application of the icepack), at the end of icepack application and after 45 minutes of recovery (Table I).

Five minutes after the treadmill run, skin, subcutaneous and muscle temperatures were $0.9+1.3^{\circ} \mathrm{C}, 1.1+0.8^{\circ} \mathrm{C}$ and $1.3+0.8^{\circ} \mathrm{C}$ higher than at rest. After 15 minutes of icepack cooling, temperatures fell in the exercised limb by $22.7+$ $1.5{ }^{\circ} \mathrm{C}$ (skin), $13.5+4.2^{\circ} \mathrm{C}$ (subcutaneous) and $9.3+5.5^{\circ} \mathrm{C}$ (muscle) and in the rested limb by $20.7+2.9^{\circ} \mathrm{C}$, (skin), 11.4 $+2.0^{\circ} \mathrm{C}$ (subcutaneous) and $8.7+2.6^{\circ} \mathrm{C}$ (muscle). Fortyfive minutes after removing the icepack the reduction in temperature in the exercised leg was $3.3+1.3^{\circ} \mathrm{C}$ (skin), 4.6 $+1.4^{\circ} \mathrm{C}$ (subcutaneous) and $5.3+1.6^{\circ} \mathrm{C}$ (muscle) and in the control limb, $3.2+0.8^{\circ} \mathrm{C}$ (skin), $5.0+0.7^{\circ} \mathrm{C}$ (subcutaneous) and $5.5+0.9^{\circ} \mathrm{C}$ (muscle). The fall in temperature after 15 minutes of icepack cooling and after 45 minutes of recovery was significant, $p<0.001$ for both the rested and exercised limb, as was the residual reduction in temperature after 45 minutes of recovery, $p<0.001$. No differences in cooling were noted between the rested and exercised limbs.

As exercise raised skin, subcutaneous and muscle temperature, the absolute changes in temperature produced by cooling and rewarming were referenced to the temperatures at the commencement of the icepack treatment (5 min) (Fig. 4). The fall in temperature from before application of the icepack to the end of cooling $(20 \mathrm{~min})$ was significant for both rested and exercised limbs, $p<0.001$, as was the fall in temperature between the commencement of icepack cooling and the end of the recovery period $(65 \mathrm{~min}) p<0.001$. No differences in cooling were noted between the rested and exercised limbs.

The rate of change of temperature per minute is shown in Fig. 5. No difference in the rate of change of temperature was noted between cooling and rewarming at rest or after exercise.

\section{Discussion}

The main finding of this study is that cooling of superficial muscle in response to an icepack is, on average, similar at rest and after exercise but that there are individual variations. This variability suggests that the haemodynamic and thermal alterations associated with intensive exercise may influence thermal flux at the depths measured, in some individuals.

During exercise, muscle temperature rises in response to increased metabolic activity, with a resultant increase in core temperature and arterial and venous blood temperature. ${ }^{9,16}$ Associated with this is an increase in cardiac output, circulating the warmed blood more rapidly around the body. Cooling is based on the second law of thermodynamics, with heat being transferred from a warmer body to a cooler body. For a muscle to cool, heat must be lost from muscle to adjacent cooler muscle tissue or subcutaneous fat. Subcutaneous fat will in turn lose heat to skin and finally heat will be dissipated by conduction to the icepack, and by radiation and evaporation to the atmosphere. The efficacy of conduction to the coolant is dependent on the surface area being cooled and the physical properties of the coolant. If arterial blood is warmer than cooling muscle, then the muscle will also gain heat from the arterial blood, thereby assisting in lowering core temperature. At rest there is a temperature gradient in large skeletal muscles, with the muscle tissue nearest the main feeder artery being the warmest and the most superficial muscle tissue, the coolest. ${ }^{16,30}$ During exercise this gradient is reduced, and after exercise it would be expected that as muscle cooling takes place, the gradient is re-established.

While the rate of cooling was similar before and after exercise, there was a trend for absolute cooling of skin, subcutaneous tissue and muscle to be greater after exercise than at rest, with skin and subcutaneous tissue, which was warmer after exercise, being cooler than resting skin and subcutaneous tissue at the end of the cooling period. Similarly the fall in muscle temperature was greater after exercise, but did not fall below that of resting muscle.

While the average data show a very similar response to cooling at rest and after exercise, the individual responses were not all the same. Similar variability has been reported in previous studies on rested muscle..$^{5,13,32,33}$ The variability has been attributed to the insulating effect of different thicknesses of adipose tissue, and individual differences in sympathetic response to local cooling. In this study another possibility is that the needles were not all placed at the correct depths, although every precaution was taken to ensure that they were placed correctly.

The sympatho-adrenal system is activated by exposure to an external cold stimulus, and skin cooling in rats has been shown to elicit different sympathetic responses, dependent on the rate of cooling. ${ }^{17}$ On the one hand, rapid skin cooling evokes a significant increase in plasma catecholamines with a reduction in skin catecholamines. The fall in skin catecholamines is attributed to their local release to cause vasoconstriction. Dermal vasoconstriction with an associated increase in plasma catecholamines may result in muscle arteriolar vasoconstriction with a more rapid fall in muscle temperature as seen in Fig. 2. On the other hand, slower cooling is not associated with an increase in plasma catecholamine concentration or a fall in skin concentration. With a reduction in local vasoconstriction, skin and muscle cooling would be slower as in Fig. 3. The catecholamine response to intense exercise may also play a role and this needs further investigation. It does not however appear to influence the timing of the local cooling response as the time to maximum cooling in rested and exercised muscle, while varying between subjects, was relatively constant for each subject. Differences in exercise-induced catecholamine response may however account for the inter-subject variability in muscle cooling. Cooling of skin causes a variable response in deeper tissues. The implications of this are that those who have very rapid skin cooling, while benefiting from the concomitant cooling of muscle, are potentially at risk of developing ice burns and those with a muted response are unlikely to derive the benefits expected from muscle cooling. 
What is required is a simple test that will elucidate who will have a rapid cooling response and who will have a slower and less effective response.

This study shows that cooling of superficial muscle occurs after high-intensity exercise to exhaustion. The degree of cooling is not uniform. This may be due to individual differences in the sympathetic response to cooling, which influence haemodynamic and thermoregulatory changes after exercise, although this was not measured in this study. Further studies are required to evaluate the sympathetic response to cooling after exercise and the temperature changes in deeper muscle tissue after exercise of different intensity and duration.

\section{REFERENCES}

1. Albrecht H, Schwecht M, Pollmann W, Parag D, Erasmus LP, Konig N. Local ice application in therapy of kinetic limb ataxia. Clinical assessment of positive treatment effects in patients with multiple sclerosis. Nervenarzt 1998; 69: 1066-73

2. Belitsky RB, Odam SJ, Hubley-Kozey C. Evaluation of the effectiveness of wet ice, dry ice, and cryogenic packs in reducing skin temperature. Phys Ther 1987; 67: 1080-4

3. Bleakley C, McDonough S, MacAuley D. The use of ice in the treatment of acute soft-tissue injury: a systematic review of randomized controlled trials. Am J Sports Med 2004; 32: 251-61.

4. Blomgren I, Bagge $U$, Johansson BR. Effects of cooling after scald injury to a dorsal skin fold of mouse. Scand J Plast Reconstr Surg 1985; 19: 1-9.

5. Borken $\mathrm{N}$, Bierman $\mathrm{W}$. Temperature changes produced by spraying with Ethyl Chloride. Arch Phys Med Rehabil 1955; 36: 288-90.

6. Deal DN, Tipton J, Curl WW, Smith TL. Ice reduces edema. A study of microcascular permeability in rats. J Bone Joint Surg 2002; 84-A: 1573-8.

7. Enwemeka CS, Allen C, Avila P, Bina J, Konrade J, Munns S. Soft tissue thermodynamics before, during, and after cold pack therapy. Med Sci Sports Exerc 2002; 34: 45-50.

8. Gass EM, Gass GC. Rectal and esophageal temperatures during upper and lower body exercise. Eur J Appl Physiol 1998; 78: 38-42.

9. Godek SF, Godek JJ, Bartolozzi AR. Thermal responses in football and cross country athletes during their respective practices in a hot environment. J Athl Train 2004; 39: 235-40.

10. Ho SS, Illgen RL, Meyer RW, Torok PJ, Cooper MD, Reider B. Comparison of various icing times in decreasing bone metabolism and blood flow in the knee. Am J Sports Med 1995; 23: 74-6.

11. Hochberg J. A randomized prospective study to assess the efficacy of two cold-therapy treatments following carpal tunnel release. J Hand Ther 2001; 14: 208-15.

12. Hubbard TJ, Denegar CR. Does cryotherapy improve outcomes with soft tissue injury? J Athl Train 2004; 39: 278-9.

13. Johnson DJ, Moore S, Moore J, Oliver RA. Effect of cold submersion on intramuscular temperature of the gastrocnemius muscle. Phys Ther 1979; 59: 1238-42

14. Jutte LS, Merrick MA, Ingersoll CD, Edwards JE. The relationship between intramuscular temperature, skin temperature, and adipose thickness during cryotherapy and rewarming. Arch Phys Med Rehabil 2001; 82: 845-50.

15. Kanui TI. Thermal inhibition of nociceptor-driven spinal cord neurones in the cat: a possible neuronal basis for thermal analgesia. Brain Res 1987; 402: $160-3$

16. Kenny GP, Reardon FD, Zaleski W, Reardon ML, Haman F, Ducharme MB Muscle temperature transients before, during and after exercise measured using an intramuscular multisensor probe. J Appl Physiol 2003; 94: 2350

17. Kozyreva TV, Tkachenko EY, Kozaruk VP, Latysheva TV, Gilinsky MA. Effects of slow and rapid cooling on catecholamine concentration in arterial plasma and the skin. Am J Physiol 1999; 276: R1668-72.

18. Lee SU, Bang MS, Han TR. Effect of cold air therapy in relieving spasticity: applied to spinalized rabbits. Spinal Cord 2002; 40: 167-73.

19. Lightfoot E, Verrier M, Ashby P. Neurophysiological effects of prolonged cooling of the calf in patients with complete spinal transection. Phys Ther 1975; 55: 251-8.

20. MacAuley DC. Ice therapy: how good is the evidence? Int J Sports Med 2001; 22: 379-84

21. Mars M. The metabolic demands of portage in kayak marathons. $S$ Afr $J$ Sports Med 1995; 4: 15-7.

22. McMaster WC, Liddle S, Waugh TR. Laboratory evaluations of various cold therapy modalities. Am J Sports Med 1978; 6: 291-4.

23. Menth-Chiari WA, Curl WW, Paterson-Smith B, Smith TL. Microcirculation of striated muscle in closed soft tissue injury: effect on tissue perfusion, inflammatory cellular response and mechanisms of cryotherapy. A study in rat by means of laser Doppler flow-measurements and intravital microscopy. Unfallchirurg 1999; 102: 691-9.

24. Merrick MA, Jutte LS, Smith ME. Cold modalities with different thermodynamic properties produce different surface and intramuscular temperatures. J Athl Train 2003; 38: 28-33.

25. Merrick MA, Knight KL, Ingersoll CD, Potteiger JA. The effects of ice and compression wraps on intramuscular temperatures at various depths. $J$ Athl Train 1993; 28: 236-45.

26. Merrick MA, Rankin JM, Andres FA, Hinman CL. A preliminary examination of cryotherapy and secondary injury in skeletal muscle. Med Sci Sports Exerc 1999; 31: 1516-21.

27. Myrer WJ, Myrer KA, Measom GJ, Fellingham GW, Evers SL. Muscle temperature is affected by overlying adipose when cryotherapy is administered. J Athl Train 2001; 36: 32-6.

28. Oosterveld FG, Rasker JJ. Treating arthritis with locally applied heat or cold. Semin Arthritis Rheum 1994; 24: 82-90.

29. Otte JW, Merrick MA, Ingersoll CD, Cordova ML. Subcutaneous adipose tissue thickness alters cooling time during cryotherapy. Arch Phys Med Rehabil 2002; 83: 1501-5.

30. Saltin B, Gagge AP, Stolwijk JA. Muscle temperature during submaximal exercise in man. J Appl Physiol 1968; 25: 679-88.

31. Swenson C, Sward L, Karlsson J. Cryotherapy in sports medicine. Scand J Med Sci Sports 1996; 6: 193-200.

32. Waylonis GW. The physiological effects of ice massage. Arch Phys Med Rehabil 1967; 48: 37-42.

33. Wolf SL, Basmajian JV. Intramuscular temperature changes deep to localized cutaneous cold stimulation. Phys Ther 1973; 53: 1284-88.

34. Yanagisawa O, Niitsu M, Yoshioka H, Goto K, Kudo H, Itai Y. The use of magnetic resonance imaging to evaluate the effects of cooling on skeletal muscle after strenuous exercise. Eur J Appl Physiol 2003; 89: 53-62. 